\title{
The Assessment of Ice-snow Tourism Resources Value and Its Realization Degree
}

\author{
Weiwei $\mathrm{Wu}^{1}$, Yexin $\mathrm{Zhu}^{1}$, Chunyan Zhang ${ }^{2}$ \\ ${ }^{1}$ School of management, Harbin Institute of Technology, Harbin 150001, China; ${ }^{2}$ Heilongjiang Province Tourism Agency, Harbin \\ 150001, China. \\ Email: zhuyexin2010@gmail.com
}

Received May, 2013

\begin{abstract}
The development of the ice-snow tourism needs a scientific and effective method to assess the value of ice-snow tourism resource and its realization degree effectively and reasonability. Based on the analysis of expectation value and realization value of ice-snow tourism resource, this paper designs a three-dimension assessment index system and constructs the method of assessing the value of ice-snow tourism resource and its realization degree. Finally using ISW scenic area in Heilongjiang Province as an example for empirical analysis, the results show that the method can be effective in assessing the value of ice-snow tourism resource and its realization degree.
\end{abstract}

Keywords: Ice-snow Tourist Resources; Value Assessment; Realization Degree

\section{Introduction}

China's tourism industry has made considerable development since the reform and opening up, and more and more tourists prefer specialized tourism such as sport tourism than simply sightseeing-type tourism. Especially after the "World Conference on Sport and Tourism" was held by World Tourism Organization and International Olympic Committee, sport tourism is becoming a new focus [1]. As an important part of sport tourism, ice-snow tourism is one of the most rapidly developing tourism. Now China has built up nearly 200 ski resorts and earned more than one billion per year. Experts expect that ice-snow tourists in China will reach 13 million and occupy $1 \%$ of the total population [2].

Ice-snow tourism resource value refers to the sum of different values in the processes of the ice-snow tourism operators developing and managing ice-snow tourism resource, and attracting tourists to consume it. It is significant for ice-snow tourism resource value to measure whether ice-snow scenic spots have the potential to be developed [3]. In China at present, the scale of ice-snow tourism is enlarging rapidly, whereas developers lack effective and scientific method of evaluating ice-snow tourism resource value, and cannot fully understand the development degree of ice-snow tourism resource, which leads to the wasting, the predatory exploitation and repeated development of ice-snow tourism resource. All these further lead to the low economic efficiency of ice-snow tourism, and become an obstacle to gain a fur- ther development of ice-snow tourism [4]. Therefore, in order to recognize the value of ice-snow tourism resources fully and develop ice-snow tourism resource reasonably, it is of great significance to establish a scientific and reasonable evaluation index system, making a macro analysis and evaluation towards ice-snow tourism resource value and its realized degree.

\section{The Value of Ice-snow Tourism Resource}

All kind of resource value has multiple-functions, and tourism value is just an additional value produced by one of these functions. This kind of value is firstly reflected during people's pursuing the comfortable life, and then is promoted gradually with the strengthening of the source's scarcity and is known and selected by more people. When this resource value is selected, it also means it is being produced and realized. The tourism value of ice-snow resource is first reflected when people gain relaxation and an understanding of exotic through touring. From the economic point of view, the value of ice and snow tourism resource is more essentially reflected as a willingness to pay when people want to gain a comfortable environment, spectacular enjoyment, or cultural influence. Thus, to understand the value of ice-snow resource, must emphasis not only the additional value of the resource, but also the essential attributes. From this perspective, tourism resource value is mostly reflected through expectation value (EX) and realization value (RX). 
Expectation value is the potential value of ice-snow tourism resource. Ice-snow tourism resource value is influenced by the environment and resource it relied on. Therefore, we should have a clear acknowledge towards the resource subject of ice-snow tourism system and the environment, time, and space resource factor it relies on to grasp the ice-snow tourism resource value accurately. From this we can understand that a symbiotic relationship exists between ice-snow tourism resource and environment resource, and time and space resource is also dynamic factors to influent tourism quality and preferences of tourists. This four resource factors are contained in the potential value of ice-snow tourism resource, and can decide what the largest value ice-snow tourism resource value is expected to attain to some.

Realization value is the value that ice-snow tourism value is actually reflected or realized. Realization value is closely related to the interaction between the subjective and objective bodies of ice-snow tourism resource. Ice-snow tourism resource is the subjective body of ice-snow tourists and tour operators. Tourists and tour operators are also subject and object with each other the same time. In the process to get the active awareness and practice activity of the subject and object, ice-snow tourism resource value can be achieved. Ice-snow tourism resource developers realize the value of the tourism resource by collecting information of tourists and investigating tourism resource. On this basis, they implement their development towards tourism resource and practice management (including marketing, maintenance and service, etc). By transferring the temporary tenure of icesnow tourism facilities, ice-snow tourism products and services to tourists to realize its economic value, developers can re-recognize the value. Tourists can recognize and realize the ice-snow tourism resource value through obtaining the temporary tenure of the processed tourism products to visit and experience activities. From the ice-snow tourists' point of view, the value of ice-snow tourism resource is more essentially reflected as a willingness to pay when tourists want to gain a comfortable environment, spectacular enjoyment, or cultural influence. On the other side, from the ice-snow tourism resource operators, they paid effort during the process of developing and managing the ice-snow tourism resource. According to the Marx 's Labor Value, they created value. For the ice-snow tourism resource itself has the feature of scarcity and the utility to meet the demand of tourists, which is conform to the subjective utility theory of value of western economics about conditions of product's worth. Therefore, we can consider that as a kind of natural resource, ice-snow tourism resource itself possesses value. Ice-snow tourism resource is the subjective body of ice-snow tourists and tour operators. Tourists and tour operators are also subject and object each other the same time. The Knowing and practicing activity are cycling all the time between the two and interplaying each other.

(See Figure 1)

In short, ice-snow tourism resource value will be influenced by the environment and resource, under the effect of dynamic, coordination, and coupling mechanism, the resource value system starts to take shape and combine the environment, time, and space resource value it relies on efficiently. However, ice-snow tourism resource value could not exist without the demand of the subject, thus the value can only be realized only by perceiving the subject \& object of ice-snow tourism resource activity and practicing. Realized value / expected value is called realized degree $(\beta)$, which can represent the development level and result of the ice-snow tourism resource.

As a natural tourism resource, the ice-snow tourism resource value can be reflected in the aspects of size and diversity, popularity and influence, specialty of landscapes, suitability for recreation and quality of service, etc. Taking the regional and seasonal characteristics of

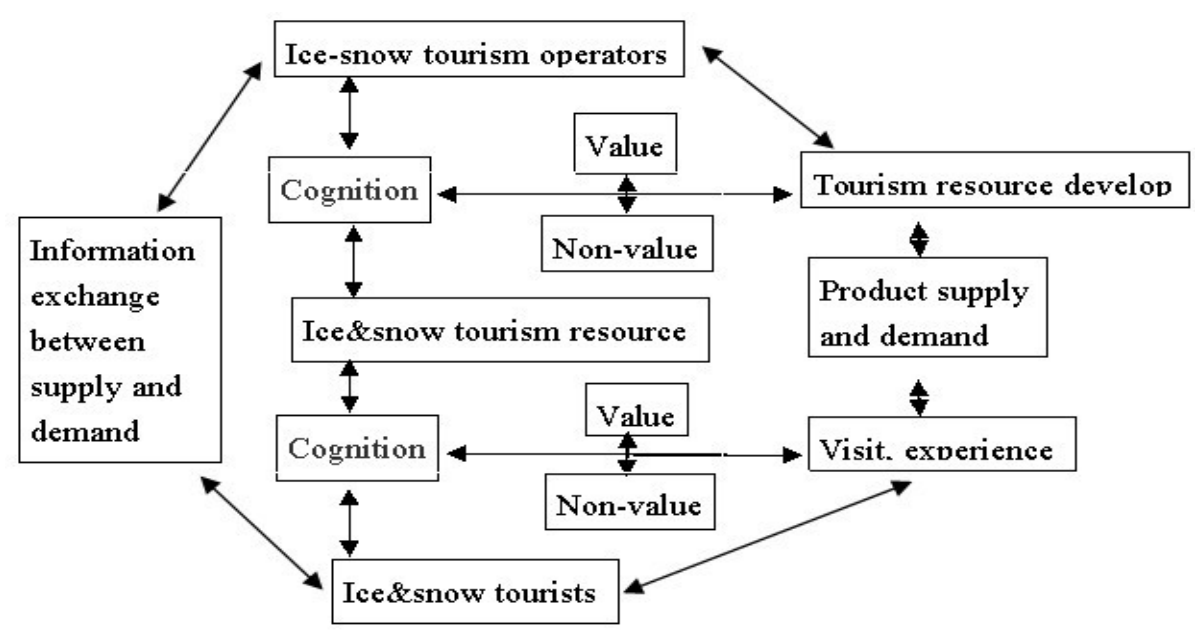

Figure 1. Ice-snow tourism resource value cognitive model. 
ice-snow tourism resource into account, ice-snow tourism resource value is related to the indicators of its applicable tourism range and period. At the same time, as a cultural tourism resource, ice-snow tourism resource has a strong cultural connotation. On one hand it reflects from the ice-snow art, clothing culture, architectural culture, eating culture, entertainment culture, and scientific and technological culture, etc. Formally, ice-snow art is the most important level, which shows the artistic side of design of ice-snow landscape can reflect the value of icesnow tourism resource. On the other hand, it reflected from the ice-snow tourism object culture, such as icesnow tourism resource, facilities, products, and the culture connotation that the ice-snow tourism managers show during the management process. Ice-snow tourism resource value can be reflected by tourism cultural heterogeneity, the conceptualization of the theme culture, participatory of the designed tourism project and suitability to display tourism culture. Such indicators can reflect the ice-snow tourism resource value. In addition, to achieve the sustainable development of the ice-snow tourism resource, it is necessary to protect the ecological environment, to maintain the integrity, and enhance the coordination of it. Ice-snow tourism scenic landscape design should pay attention to maintain the original ecological environment, reflecting the ecological atmosphere to be corresponded with the landscape and the theme culture. So it can be put forward that the integrity of ecological resource and the ecologic of landscape design index can reflect the value of ice-snow tourism resource ${ }^{[4]}$. Based on the foregoing analysis, it can be considered that the ice-snow tourism resource value factors mainly includes three dimensions: economic, cultural and ecological dimensions (see Figure 2).

Accordingly, ice-snow tourism resource can be de- composed into economic value, cultural value and ecological value. Based on the natural reproduction capacity of ice-snow tourism resource, economic value is the necessary labor time to protect, recover and add value to ice-snow reproduction, which reflects the investing value of society. Cultural value mainly points to resource values that can satisfy the mankind's spirit cultural and moral need, such as the artistic of designed landscape, tourism cultural heterogeneity, theme culture concept, etc. Ecological value mainly reflects the elements of ice-snow tourism resource value on the ecological aspect. Such as ecological landscape design, integrity of ecological resources, environmental protection, and coordination of ecological environment. By referencing domestic and foreign researchers' results [5-7], it is possible to build the ice-snow tourism resource value evaluation system (Table 1).

\section{The Evaluation Model of Ice-snow Tourism Resource Value}

Weight of ice-snow tourism resource value evaluation index is determined by analytic hierarchy process (AHP). In order to determine the weight of each index, questionnaires are given out to 12 ice-snow tourism scholars and practitioners, to get a comparison between different levels of evaluation importance. Experts will give the two evaluation indicators' relative importance based on their judgment, the value space is an integer between 1 to 9 , and $u_{i j}=1 / u_{j i}$. The value criterion been taken is shown in Table 2.

Process the data obtained from the investigation and get the mean value, constructing pairwise comparison judgment matrix, and use Analytic Hierarchy Process to calculate the weight of each arrange evaluation index. The result is shown in Table 3 .

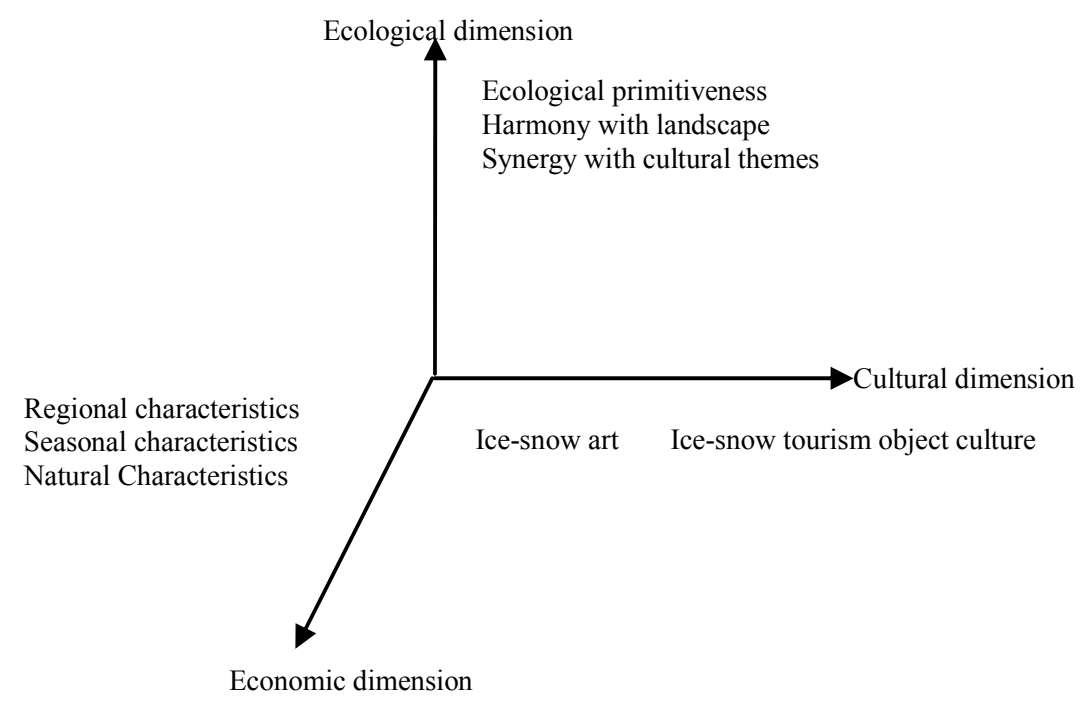

Figure 2. Three-dimension structure of ice-snow tourism resources value. 
Table 1. Ice-snow tourism resource value evaluation system.

\begin{tabular}{|c|c|c|c|}
\hline $\begin{array}{l}\text { Primary } \\
\text { Index }\end{array}$ & $\begin{array}{l}\text { Secondary } \\
\text { Index }\end{array}$ & Third level Index & $\begin{array}{c}\text { Analysis of } \\
\text { variance }\end{array}$ \\
\hline \multirow{16}{*}{$\begin{array}{l}\text { Ice }- \text { snow } \\
\text { tourism } \\
\text { resource } \\
\text { value }(\mathrm{X})\end{array}$} & \multirow{7}{*}{$\begin{array}{l}\text { Economic } \\
\text { Value }\left(X_{1}\right)\end{array}$} & Specialty of Landscapes & $\mathrm{X}_{11}$ \\
\hline & & Suitability for recreation & $\mathrm{X}_{12}$ \\
\hline & & Size and diversity & $\mathrm{X}_{13}$ \\
\hline & & Popularity and influence & $\mathrm{X}_{14}$ \\
\hline & & Appropriate travel period & $\mathrm{X}_{15}$ \\
\hline & & Appropriate travel area & $\mathrm{X}_{16}$ \\
\hline & & Service quality & $\mathrm{X}_{17}$ \\
\hline & \multirow{5}{*}{$\begin{array}{l}\text { Cultural } \\
\text { Value }\left(\mathrm{X}_{2}\right)\end{array}$} & Landscape design & $\mathrm{X}_{21}$ \\
\hline & & $\begin{array}{l}\text { Tourism cultural } \\
\text { heterogeneity }\end{array}$ & $\mathrm{X}_{22}$ \\
\hline & & Theme culture concept & $X_{23}$ \\
\hline & & $\begin{array}{l}\text { Participatory of project } \\
\text { design }\end{array}$ & $X_{24}$ \\
\hline & & Suitability of culture show & $\mathrm{X}_{25}$ \\
\hline & \multirow{4}{*}{$\begin{array}{l}\text { Ecological } \\
\text { Value }\left(\mathrm{X}_{3}\right)\end{array}$} & $\begin{array}{l}\text { Ecological landscape } \\
\text { design }\end{array}$ & $X_{31}$ \\
\hline & & $\begin{array}{l}\text { Integrity of } \\
\text { ecological resources }\end{array}$ & $\mathrm{X}_{32}$ \\
\hline & & Environmental protection & $\mathrm{X}_{33}$ \\
\hline & & $\begin{array}{l}\text { Coordination with } \\
\text { ecological environment }\end{array}$ & $\mathrm{X}_{34}$ \\
\hline
\end{tabular}

Table 2. Evaluation standards.

\begin{tabular}{cl}
\hline Score & \multicolumn{1}{c}{ Explanation } \\
\hline 1 & $u_{i}$ is equally important compared with $u_{j}$ \\
3 & $u_{i}$ is slightly more important compared with $u_{j}$ \\
5 & $u_{i}$ is obviously more important compared with $u_{j}$ \\
7 & $u_{i}$ is far more important compared with $u_{j}$ \\
9 & $u_{i}$ is extremely more important compared with $u_{j}$ \\
$2,4,6,8$ & The medianbetween 1-3,3-5, 5-7,7-9 \\
\hline
\end{tabular}

Table 3. Evaluation index weight value.

\begin{tabular}{cccc}
\hline \multicolumn{2}{c}{ Index } & \multicolumn{2}{c}{ Weight } \\
\hline \multirow{4}{*}{$\mathrm{X}_{1}$} & $\mathrm{X}_{11}$ & 0.112 & \\
& $\mathrm{X}_{12}$ & 0.123 & \\
& $\mathrm{X}_{13}$ & 0.123 & 0.50 \\
& $\mathrm{X}_{14}$ & 0.141 & \\
& $\mathrm{X}_{15}$ & 0.167 & \\
& $\mathrm{X}_{16}$ & 0.167 & \\
& $\mathrm{X}_{17}$ & 0.167 & \\
& $\mathrm{X}_{21}$ & 0.168 & \\
$\mathrm{X}_{2}$ & $\mathrm{X}_{22}$ & 0.198 & \\
& $\mathrm{X}_{23}$ & 0.198 & \\
& $\mathrm{X}_{24}$ & 0.222 & \\
& $\mathrm{X}_{25}$ & 0.214 & \\
& $\mathrm{X}_{31}$ & 0.297 & \\
& $\mathrm{X}_{32}$ & 0.203 & \\
& $\mathrm{X}_{33}$ & 0.297 & \\
& $\mathrm{X}_{34}$ & 0.203 & \\
\hline
\end{tabular}

The evaluation models of, economic value, cultural value, and ecological value of ice-snow tourism resource value are shown as following.

$$
\begin{gathered}
X_{1}=0.112 X_{11}+0.123 X_{12}+0.123 X_{13}+0.141 X_{14} \\
+0.167 X_{15}+0.167 X_{16}+0.167 X_{17} \\
X_{2}=0.168 X_{21}+0.198 X_{22}+0.198 X_{23} \\
\quad+0.222 X_{24}+0.214 X_{25} \\
X_{3}=0.297 X_{31}+0.203 X_{32}+0.297 X_{33}+0.203 X_{34} \\
X=0.50 X_{1}+0.30 X_{2}+0.20 X_{3}
\end{gathered}
$$

$X \geq 90$ shows that ice-snow tourism resource value is very high and has a very good potential for development; $70 \leq X \prec 90$ shows that ice-snow tourism resource value is relatively high and has a good potential for development, $50 \leq X \prec 70$ shows ice-snow tourism resource value is ordinary and also has an ordinary potential for development; $30 \leq X \prec 50$ shows the ice-snow tourism resource value is low and has a bad potential for development; $X \prec 30$ shows ice-snow tourism resource value is very low and does not have enough potential for development

The expect value ( $E X)$ and realized value $(R X)$ of ice-snow tourism resource value can be gotten by formula (1), formula (2) and formula (3). RX/EX is the realized degree $(\beta)$, which can be shown as:

$$
\beta=\frac{R X}{E X}
$$

Thus, the realized degree of economic value is:

$$
\beta_{1}=\frac{R X_{1}}{E X_{1}}
$$

The realized degree of cultural value is:

$$
\beta_{2}=\frac{R X_{2}}{E X_{2}}
$$

The realized degree of ecological value is:

$$
\beta_{3}=\frac{R X_{3}}{E X_{3}}
$$

$\beta \geq 0.9$ shows the effect of ice-snow tourism resource value development is very good, $0.7 \leq \beta \prec 0.9$ shows the effect is ordinary, $0.3 \leq \beta \prec 0.5$ shows the effect is bad, $\beta \prec 0.3$ shows the development result is very bad.

\section{The Empirical Analysis}

Scenic spot ISW is located in Heilongjiang Province which has an abundant ice-snow tourism resource. Icesnow tourism activity is held every year with a specific theme. In this scenic spot, the essence of ice-snow art is 
concentrated. It is one of the biggest ice-snow scenic spot in the world and has a lot of ice-snow patches and various forms of recreation and entertainment. The ice-snow tourism resource in scenic spot A includes natural tourism resource and cultural tourism resource, which can reflect the categories and characteristics of ice-snow tourism resource, and also is a typical accumulation area of ice-snow tourism resource.

\subsection{Data}

In order to obtain the required data for evaluation, icesnow tourism resource value evaluation questionnaire is designed based on the ice-snow tourism resource value evaluation index system. 500 questionnaires are given out to tourists in ISW scenic area, of which 448 is valid. The effective rate is $89.6 \%$. The questionnaire is divided into three parts. The first part is the value of tourism resource evaluation survey in ISW scenic area of Heilongjiang Province. Tourists grade each indicator that is been designed with a full mark of 100.The second part is a survey of realized degree in ISW scenic area in Heilongjiang Province. Tourists grade the realization degree of each indicator. The third part shows the basic situation of the respondents, such as place of origin, age, education degree, etc.

Cronbach alpha is used to test the reliability of the questionnaire, and the expert investigation method and factor analysis method are used to test the content validity and structure validity of the questionnaire. The alpha reliability coefficient is over 0.8 , which indicates that the indicators designed in the questionnaire have acceptable reliability. Many previous research results are applied in the design of the questionnaire, and the items of the questionnaire are revised by the expert investigation method to make sure that the selected items represent the contents. So that the questionnaire has good content's validity. On conducting the structure validity to each index, it is found that the value of KMO is greater than 0.5 , which shows that there exist seven common factors, which are the same as the secondary indicators of the index system. Thus, the questionnaire design has good structure validity.

\subsection{Results}

Processing the data of indicators collected from the first and the second part in the questionnaire and calculate the mean, and then combining the index weights equation (1)-(8) obtained in Table 3, we can calculate the economic value, cultural value, and ecological value of ice-snow tourism resource, the ice-snow tourism resource value and the realization degree. The result is shown in Table 4.
Table 4. Evaluation result.

\begin{tabular}{ccccc}
\hline Indicators & $\begin{array}{c}\text { Economic } \\
\text { value }\end{array}$ & $\begin{array}{c}\text { Cultural } \\
\text { value }\end{array}$ & $\begin{array}{c}\text { Ecological } \\
\text { value }\end{array}$ & $\begin{array}{c}\text { Ice-snow tourism } \\
\text { resource value }\end{array}$ \\
\hline RX & 66.54 & 36.39 & 49.30 & 54.19 \\
EX & 80.30 & 90.87 & 85.16 & 84.34 \\
$\begin{array}{c}\text { Realization } \\
\text { degree }\end{array}$ & $82.9 \%$ & $40.10 \%$ & $57.90 \%$ & $64.20 \%$ \\
\hline
\end{tabular}

It can be seen from table 4 that the expected economic value of ice-snow tourism resource of ISW scenic area is 80.30 , expected cultural value is 90.87 , expected ecological value is 84.34. ISW scenic area obsesses a fine ice-snow tourism resource and fine development potential reflected from the data above. From the composition of the ice-snow tourism resource value, cultural value has the highest score, followed by the ecological value, economic value as the last. This shows that, compared with the economic value, ISW scenic area has a higher cultural and ecological value. The result of this evaluation requires managers in ISW scenic area that more attention should be paid to cultural values and ecological value than economic value.

The realization value of the economic value of ISW scenic area is 66.54 , with cultural value 36.39 , and ecological value 49.30 . The realization value of ice-snow tourism resource is 54.19. The realization degree of ice-snow tourism resource of ISW scenic area is $64.20 \%$, which shows the realization degree of ice-snow tourism resource value of ISW scenic area is not high and has an ordinary development result. The realization degree of economic value is $82.90 \%$, with cultural value $40.10 \%$, and ecological value $57.90 \%$. This indicates that the economic value of ice-snow tourism resource value of ISW scenic is fully developed and has a fine development result. On the other hand, the development of ecological and cultural values is not effective, especially cultural values, which still has a great room for improvement. Therefore, ISW scenic area will continuing increase the development of the ice-snow tourism resource value, especially to strengthen the development of cultural and ecological value, striving to improve the realization degree.

\section{Conclusions}

Based on the analysis of expectation value and realization value of ice-snow tourism resource, this paper designs an analytical framework of three-dimension including economic value, cultural value and ecological value combined with the characteristic of ice-snow tourism resource. From the three aspects, an assessment index system is designed, including 3 hierarchies, 16 indicators. Comparisons are made with the studies by differ- 
ent scholars in the same field from home and abroad when choosing indicators to ensure that the selected indicators are comprehensive, scientific and rational $[8,9]$.

Analytic Hierarchy Process is used to determine the index weight, and based on this, economic value, cultural value, ecological value, as well as ice-snow tourism resource value and are analyzed, the model of ice-snow tourism resource value is constructed, and the development of ice-snow tourism resource value is assessed. It can be seen from the evaluation and analysis of ice-snow tourism resource value of ISW scenic area in Heilongjiang province that the evaluation model and methods developed in this paper can make scientific and reasonable evaluation towards ice-snow tourism resource value and are beneficial to improving the result of ice-snow tourism resource development.

This paper only provides a preliminary exploration on the assessment of the ice-snow tourism resource value, and there are many other important issues need to be further studied. For example, the interaction and coupling relationships among the three dimensions have a certain influence on the ice-snow tourism resource value, and can be included into the index system in further research to achieve a more precise evaluation result.

\section{Acknowledgements}

The work described in this paper is supported by the Philosophy and Social Science Project in Heilongiiang Province (08C059).

\section{REFERENCES}

[1] L. Wang, "A Summary on the Ice-Snow Tourism Devel- opment and Research at Home and Abroad," Ecological Economy, Vol. 6, 2010, pp. 66-69.

[2] Y. N. Tan, “A Primary Exploration of Ice-snow Tourism Experience Marketing Tactics in Changchun, Economic Vision, Vol. 11, 2006, pp. 39-40.

[3] H. Elsasser and P. Messerli, "The Vulnerability of the Snow Industry in the Swiss Alps," Mountain Research and Development, Vol. 21, No. 4, 2001, pp. 335-339. doi:10.1659/0276-4741(2001)021[0335:TVOTSI]2.0.CO; $\underline{2}$

[4] Y. S. Tang, "Development Circumstance Analysis and Innovation Strategy of Chinese Ski Industry," China Winter Sports, Vol. 1, 2009, pp. 83-87

[5] W. W. Wu, Q. Deng and C. Y. Zhang, "Study on the Coupling Mechanism of the Ice-Snow Tourism Resource Value and External Environment," Proceedings of Geology Resource Management and Sustainable Development, 2009, pp. 339-343.

[6] H. Elsasser, P. Messerli, "The Vulnerability of the Snow Industry in the Swiss Alps. Mountain," Research and Development, Vol. 4, 2001, pp. 335-339. doi:10.1659/0276-4741(2001)021[0335:TVOTSI]2.0.CO; $\underline{2}$

[7] C. Y. Zhang, Y. Q. Hu and M. Du, "Ice-snow Tourism Culture Shaping during Tourism Resource Development Evaluation," Management World, Vol. 4, 2008, pp. 173-174.

[8] C. Wolfsegger, S. Gössling and D. Scott, "Climate Change Risk Appraisal in the Austrian Ski Industry," Tourism Review International, Vol. 12, No. 1, 2008, pp. 13-23. doi: $10.3727 / 154427208785899948$

[9] C. K. Lee and S. Y. Han, "Estimating the Use and Preservation Values of National Parks' Tourism Resources using a Contingent Valuation Method," Tourism Management, Vol. 23, No. 5, 2002, pp. 531-540. doi:10.1016/S0261-5177(02)00010-9 